$\stackrel{N / N}{=}$

Global burnals Inc.

की

\title{
Development and Validation of a Stability-Indicating RP-HPLC Method for the Simultaneous Determination of Sofosbuvir, Velpatasvir, and Voxilaprevir in Tablet Formulation
}

By Deepthi R \& Gowri Sankar D

Abstract- Objective: The present study aimed to develop a stability-indicating reverse-phase high performance-liquid chromatography (RP-HPLC) method for the estimation of Sofosbuvir, Velpatasvir, and Voxilaprevir in tablet dosage form and validated in accordance with $\mathrm{ICH}$ guidelines.

Methods: The optimized conditions for the developed RP-HPLC method are Agilent C18 (250 $\mathrm{mm} \times 4.6 \mathrm{~mm}, 5 \mu)$ column maintained at $30^{\circ} \mathrm{C}$ with a mobile phase consisting of Buffer $(0.1 \% \mathrm{OPA})$ and Acetonitrile taken in the ratio $55: 45 \% \mathrm{v} / \mathrm{v}$ on isocratic mode at flow rate $1.0 \mathrm{ml} / \mathrm{min}$. The sample was detected at $220 \mathrm{~nm}$.

Results: The retention time of Sofosbuvir, Velpatasvir, and Voxilaprevir was found to be $2.17,2.731$ and $3.55 \mathrm{~min}$ respectively. The developed method was validated for accuracy, precision, specificity, ruggedness, robustness and solution stability.

Keywords: stability- indicating, method development, validation, RP-HPLC, sofosbuvir.

GJMR-B Classification: NLMC Code: QV 55

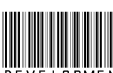

Strictly as per the compliance and regulations of:

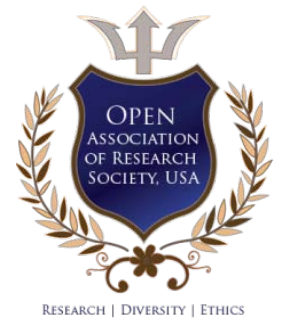

(C) 2020. Deepthi R \& Gowri Sankar D. This is a research/review paper, distributed under the terms of the Creative Commons Attribution-Noncommercial 3.0 Unported License http://creativecommons.org/licenses/by-nc/3.0/), permitting all non-commercial use, distribution, and reproduction in any medium, provided the original work is properly cited. 


\title{
Development and Validation of a Stability-Indicating RP-HPLC Method for the Simultaneous Determination of Sofosbuvir, Velpatasvir, and Voxilaprevir in Tablet Formulation
}

\author{
Deepthi $R^{\alpha}$ \& Gowri Sankar D ${ }^{\sigma}$
}

\begin{abstract}
Objective: The present study aimed to develop a stability-indicating reverse-phase high performance-liquid chromatography (RP-HPLC) method for the estimation of Sofosbuvir, Velpatasvir, and Voxilaprevir in tablet dosage form and validated in accordance with ICH guidelines.
\end{abstract}

Methods: The optimized conditions for the developed RPHPLC method are Agilent C18 $(250 \mathrm{~mm} \times 4.6 \mathrm{~mm}, 5 \mu)$ column maintained at $30^{\circ} \mathrm{C}$ with a mobile phase consisting of Buffer(0.1\%OPA) and Acetonitrile taken in the ratio $55: 45 \% \mathrm{v} / \mathrm{v}$ on isocratic mode at flow rate $1.0 \mathrm{ml} / \mathrm{min}$. The sample was detected at $220 \mathrm{~nm}$.

Results: The retention time of Sofosbuvir, Velpatasvir, and Voxilaprevir was found to be $2.17,2.731$ and $3.55 \mathrm{~min}$ respectively. The developed method was validated for accuracy, precision, specificity, ruggedness, robustness and solution stability. The method obeyed Beer's law in the concentration range of $10 \mu \mathrm{g} / \mathrm{ml}-60 \mu \mathrm{g} / \mathrm{ml}$ for Sofosbuvir, $2.5 \mu \mathrm{g} / \mathrm{ml}-15 \mu \mathrm{g} / \mathrm{ml}$ for Velpatasvir and $2.5 \mu \mathrm{g} / \mathrm{ml}-15 \mu \mathrm{g} / \mathrm{ml}$ for Voxilaprevir with a correlation coefficient of 0.999 for Sofosbuvir, Velpatasvir, and Voxilaprevir respectively.

Forced degradation studies were conducted by exposing the drug solution to various stress conditions such as acidic, basic, peroxide, neutral, photolytic and thermal conditions. The net degradation was found to be within the limits, indicating that the drug is stable in stressed conditions.

Conclusion: The developed method for the estimation of Sofosbuvir, Velpatasvir, and Voxilaprevir can be utilized for the routine analysis of the pharmaceutical dosage form.

Keywords: stability- indicating, method development, validation, RP-HPLC, sofosbuvir.

\section{INTRODUCTION}

$\mathrm{H}$ epatitis C [1] is a liver infection which is caused by the Hepatitis $C$ virus. The hepatitis $C$ virus is a blood-borne virus and the most common modes of infection are through exposure to small quantities of infected blood. Globally, around 70 million people were suffering from Hepatitis $\mathrm{C}$ infection. Antiviral medicines like sofosbuvir, velpatasvir, and voxilaprevir, etc; can cure more than $95 \%$ of persons having Hepatitis C infection and reduce the causes of death.

Author $\alpha$ : Research Scholar, Department of Pharmaceutical Analysis, Andhra University, Visakhapatnam, Andhra Pradesh, India.

e-mail: deepthi.pharma7@gmail.com
Sofosbuvir [2] (Fig 1) is a nucleotide prodrug and a hepatitis $\mathrm{C}$ virus (HCV) NS5B polymerase inhibitor with potential HCV inhibiting activity. Used as an antiviral drug in the treatment of Hepatitis $C$ virus. It is chemically (S)-Isopropyl 2-((S)-(((2R,3R,4R,5R)-5-(2,4dioxo3,4 dihydropyrimidin $1(2 \mathrm{H}) \mathrm{yl}) 4$ fluoro3hydroxy4methyltetrahyd rofuran2yl)methoxy)(phenoxy)phenylamino) propanoate.<smiles>CC(C)OC(=O)[C@H](C)NP(=O)(OCC1OC2O[C@H]1C(O)[C@]2(F)n1ccc(=O)[nH]c1=O)Oc1ccccc1</smiles>

Figure 1: Structure of Sofosbuvir

Velpatasvir [3] (Fig 2) is a NS5A inhibitor which is used together with sofosbuvir to treat chronic Hepatitis C infection. Used as an antiviral drug in the treatment of Hepatitis $\mathrm{C}$ virus. Chemically it is methyl $\{(2 S)-1-[(2 S, 5 S)-2-(9-\{2-[(2 S, 4 S)-1-\{(2 R)-2-[($ methoxy carbonyl) amino]-2-phenylacetyl $\}-4$-(methoxy methyl) pyrrolidin-2-yl]-1H-imidazol-4-yl\}-1,11-dihydro[2] benzopyrano[4',3':6,7]naphtho[1,2-d] imidazol-2-yl)-5-methylpyrrolidin-1-yl]-3-methyl-1-oxobutan-2-yl\}carbamate.

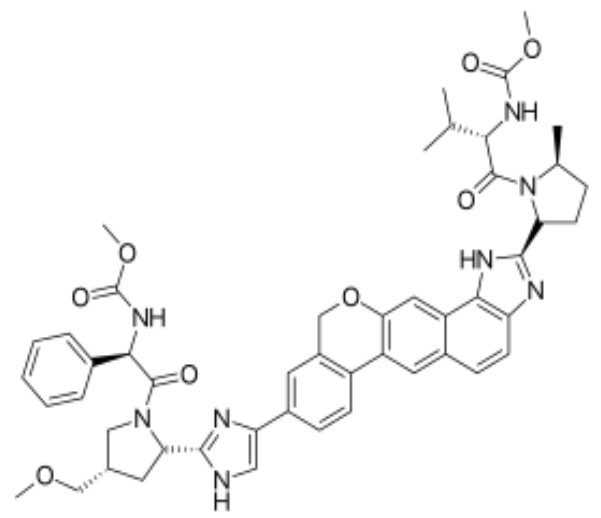

Figure 2: Structure of Velpatasvir 
Voxilaprevir [4] (Fig 3) is a protease inhibitor and acts as a transporter of polypeptide. Used as an antiviral drug in the treatment of Hepatitis $C$ virus. chemically it is $(1 \mathrm{R}, 18 \mathrm{R}, 20 \mathrm{R}, 24 \mathrm{~S}, 27 \mathrm{~S}, 28 \mathrm{~S}) \mathrm{N}[(1 \mathrm{R}, 2 \mathrm{R})$ 2(Difluoromethyl)1\{[(1methylcyclopropyl)sulfonyl]carba moyl\}cyclopropyl]-28-ethyl-13,13-difluoro-7-methoxy-24 -(2-methyl-2-propanyl)-22,25-dioxo-2,21dioxa4,11,23, 26 -tetra aza penta cyclo nonacosa-3(12),4,6,8,10pentaene-27-carboxamide.

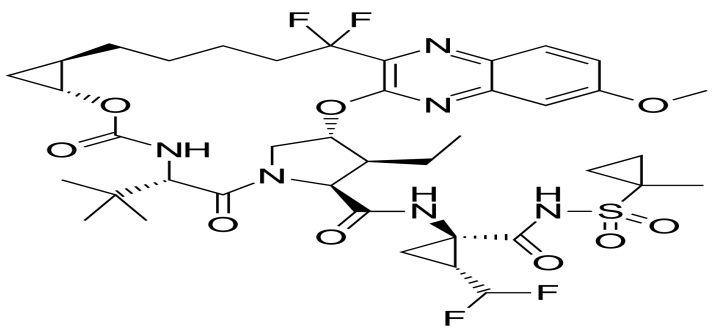

Figure 3: Structure of Voxilaprevir

As per the literature survey [5-11], it is learned that very few HPLC methods have been reported for the determination of Sofosbuvir, Velpatavir, and Voxilaprevir individually and in combination by HPLC but there is no method for stability-indicating and simultaneous estimation of all the three drugs.

Therefore, there is a need to develop a rapid and reliable Stability-indicating HPLC method for the simultaneous determination of Sofosbuvir, Velpatasvir, and Voxilaprevir in bulk and pharmaceutical dosage form.

\section{il. Materials And Methods}

\section{a) Reagents and chemicals}

Sofosbuvir, Velpatasvir and Voxilaprevir working standards were procured from spectrum pharma research solutions, Hyderabad, as a gift sample. The VOSEVI tablets were supplied by the Medindia Pharma network. All the chemicals used were of AR grade purchased from Merck, Mumbai. All the solvents used were of HPLC grade purchased from Sigma-Aldrich, Mumbai.

\section{b) Chromatographic conditions and Instruments}

WATERS HPLC 2695 SYSTEM equipped with quaternary pumps, Photo Diode Array detector, and an auto sampler integrated with Empower 2 software and Agilent C18 $(250 \mathrm{~mm} \times 4.6 \mathrm{~mm}, 5 \mu)$ column was used for the determination of Sofosbuvir, Velpatasvir, and Voxilaprevir. The optimized conditions included $0.1 \%$ Orthophosphoric acid (OPA) and acetonitrile $(55: 45 \% \mathrm{v} / \mathrm{v})$ as mobile phase run on an isocratic mode at flow rate $1.0 \mathrm{ml} / \mathrm{min}$. The column was maintained at $300 \mathrm{C}$ and detection was done at $220 \mathrm{~nm}$. Other equipment used in the method was Ultrasonic bath sonicator (BVK Enterprises) and weighing balance (Denver). c) Preparation of Diluent

A mixture of water and acetonitrile in the ratio of 50:50\% v/v was used as diluents.

d) Preparation of Mobile phase

A mixture of $0.1 \%$ orthophosphoric acid and Acetonitrile in the ratio $(55: 45 \% \mathrm{v} / \mathrm{v})$ was used as the mobile phase.

\section{e) Preparation of Standard and Sample solutions}

$20 \mathrm{mg}, 5 \mathrm{mg} \& 5 \mathrm{mg}$ of Sofosbuvir, Velpatasvir and Voxilaprevir working Standards were transferred to $50 \mathrm{ml}$ of volumetric flasks separately, 3/4th of diluents (as mentioned) was added to all the three flasks and subjected for sonication for 10 minutes. The final volume was made up with diluents to obtain a final concentration of $400 \mu \mathrm{g} / \mathrm{ml}$ of Sofosbuvir, $100 \mu \mathrm{g} / \mathrm{ml}$ of Velpatasvir, \& $100 \mu \mathrm{g} / \mathrm{ml}$ of Voxilaprevir respectively.

From the above stock solution, $1 \mathrm{ml}$ was pipetted out into a $10 \mathrm{ml}$ volumetric flask and then the final volume was made with the same diluent. $(40 \mu \mathrm{g} / \mathrm{ml}$ of Sofosbuvir, $10 \mu \mathrm{g} / \mathrm{ml}$ of Velpatasvir and $10 \mu \mathrm{g} / \mathrm{ml}$ of Voxilaprevir respectively)

10 Tablets (Vosevi) were weighed accurately and the average weight was calculated. An amount equivalent of 1 tablet was collected into a $50 \mathrm{ml}$ volumetric flask; $15 \mathrm{ml}$ of diluents was mixed and sonicated for around 30 minutes. It was then subjected to making the volume with diluents.

Filtered the solution and diluted $1 \mathrm{ml}$ of the above solution to $10 \mathrm{ml}$ with diluents. $(40 \mu \mathrm{g} / \mathrm{ml}$ of Sofosbuvir \& $10 \mu \mathrm{g} / \mathrm{ml}$ of Velpatasvir \& $10 \mu \mathrm{g} / \mathrm{ml}$ of Voxilaprevir).

\section{f) Method Validation}

The developed method was validated in compliance with International Conference on Harmonization $(\mathrm{ICH})$ guidelines $[12,13]$.

\section{g) Specificity}

The specificity of the method was determined by comparing the drug solution with the placebo solution and observed for the interference of placebo peak with drug peak.

\section{h) Accuracy}

The accuracy of the present method was determined by \%recovery. The drug solution along with the sample was prepared in three concentration levels $50 \%, 100 \%$, and $150 \%$. Then the \% recovery was calculated.

\section{i) Precision}

The precision of the method was estimated by injecting the six solutions of the standard into the HPLC system and the \% relative standard deviation (\%RSD) was calculated. 


\section{j) Linearity}

The linearity of the method was developed by preparing series of dilutions ranging from $12.5 \mu \mathrm{g} / \mathrm{ml}$ $75 \mu \mathrm{g} / \mathrm{ml}$ for Bictegravir, $50 \mu \mathrm{g} / \mathrm{ml}-300 \mu \mathrm{g} / \mathrm{ml}$ for Emtricitabine and $6.25 \mu \mathrm{g} / \mathrm{ml}-37.5 \mu \mathrm{g} / \mathrm{ml}$ for Tenofovir alafenamide respectively and injecting them into HPLC system.

\section{k) Ruggedness}

Ruggedness was determined by injecting the six solutions of the standard into HPLC for different days. The $\%$ RSD was calculated.

\section{l) Robustness}

Robustness of the method was determined by varying the optimized analytical conditions such as mobile phase composition by $\pm 5 \%$, flow rate by $\pm 0.1 \mathrm{ml} / \mathrm{min}$ and column temperature by $\pm 5^{\circ} \mathrm{C}$.

\section{m) $\angle O D$ and $L O Q$}

Calculation of limit of detection as well as Limit of quantification had been done by using standard
Equations. $\mathrm{LOD}=3.3 \times \sigma / \mathrm{S}, \mathrm{LOQ}=10 \times \sigma / \mathrm{S}$. Here $\sigma$ denotes for the standard deviation of intercepts of regression lines, $\mathrm{S}$ denotes for slope.

\section{n) Solution stability}

Solution stability was estimated by analyzing the standard drug solution after storage for 24hrs under laboratory conditions.

\section{o) Forced degradation studies}

Forced degradation studies[14] were carried out for drug by exposing the drug solution to the various stress conditions such as acidic (2N Hydrochloric acid for $30 \mathrm{~min}$ at $60^{\circ} \mathrm{C}$ ), basic ( $2 \mathrm{~N}$ Sodium hydroxide for $30 \mathrm{~min}$ at $60^{\circ} \mathrm{C}$ ), Oxidation (refluxing the drug solution with $20 \% \mathrm{H} 2 \mathrm{O} 2$ ), neutral (refluxing the drug in water for 6 at $60^{\circ} \mathrm{C}$ ), photolytic (exposing the drug solution to UV light by keeping the solution in UV chamber for 7 days or 200-watt hrs/m2 in photostability chamber), thermal (drug solution was placed in oven at $105^{\circ} \mathrm{C}$ for 6hrs) conditions.

\section{ili. Results}

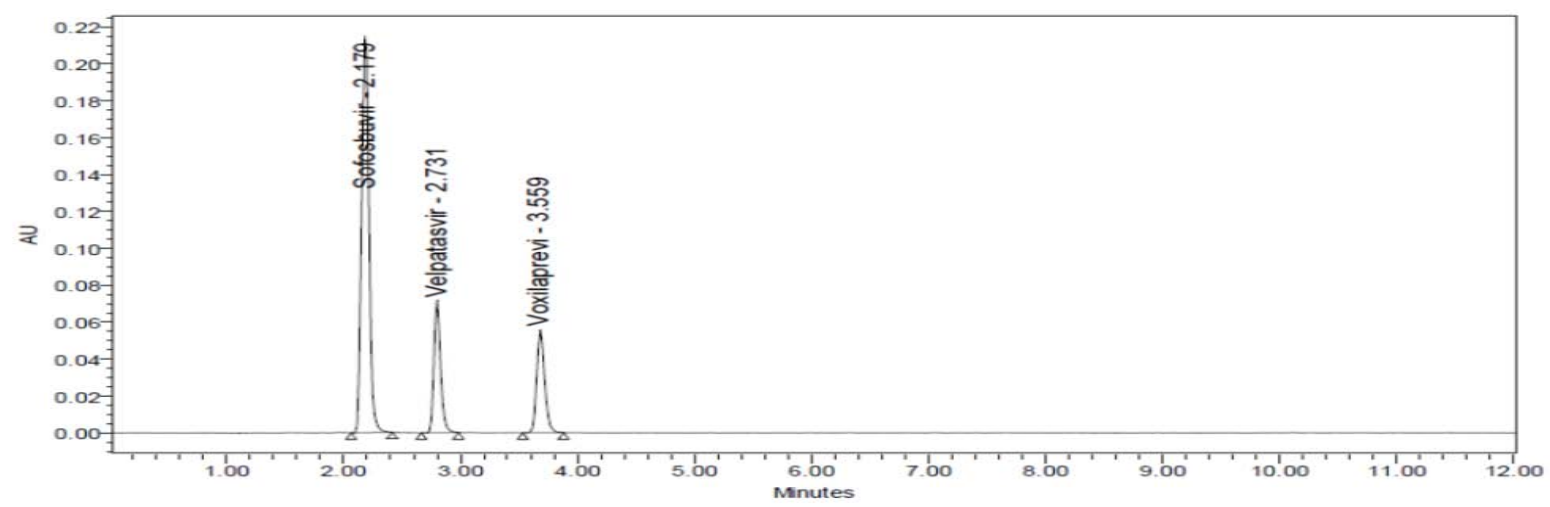

Figure 4: Optimized chromatogram of Sofosbuvir, Velpatasvir, and Voxilaprevir

Table 1: System suitability and validation parameter results

\begin{tabular}{|c|c|c|c|}
\hline \multirow[b]{2}{*}{ Parameter } & \multicolumn{2}{|c|}{ Result } & \multirow[b]{2}{*}{ Voxilaprevir } \\
\hline & Sofosbuvir & Velpatasvir & \\
\hline USP Plate count & 4088 & 10175 & 126558 \\
\hline USP Tailing factor & 1.0 & 1.2 & 1.2 \\
\hline USP Resolution & 4.5 & - & 7.2 \\
\hline Precision (\%RSD) & 0.9 & 0.8 & 0.4 \\
\hline Accuracy & $98.50-101.50$ & $98.50-101.50$ & $98.50-101.50$ \\
\hline Specificity & & Specific, No interference & \\
\hline Linearity range ( $\mu \mathrm{g} / \mathrm{ml})$ & $10-60$ & $2.5-15$ & $2.5-15$ \\
\hline Correlation coefficient, $\mathrm{r}^{2}$ & 0.999 & 0.999 & 0.999 \\
\hline $\operatorname{LOD}(\mu \mathrm{g} / \mathrm{ml})$ & 0.11 & 0.10 & 0.06 \\
\hline $\mathrm{LOQ}(\mu \mathrm{g} / \mathrm{ml})$ & 0.34 & 0.29 & 0.17 \\
\hline \multicolumn{4}{|l|}{ Ruggedness (\%RSD) } \\
\hline Day1 & 0.9 & 0.8 & 0.4 \\
\hline Day2 & 0.9 & 1.9 & 0.6 \\
\hline Robustness (\%RSD) & & & \\
\hline Flow rate - & 1.2 & 1.1 & 1.0 \\
\hline
\end{tabular}




\begin{tabular}{llll}
\hline Flow rate + & 3.4 & 3.7 & 3.7 \\
Column temperature - & 2.8 & 2.7 & 2.9 \\
Column temperature + & 2.2 & 2.4 & 2.2 \\
Mobile phase - & 3.8 & 3.4 & 3.2 \\
Mobile phase + & 2.4 & 2.7 & 2.4 \\
Solution stability (\%RSD) & & & \\
$(0 \mathrm{hrs})$ & 1.0 & 0.6 & 1.0 \\
$(24 \mathrm{hrs})$ & 0.9 & 1.0 & 0.6 \\
\hline
\end{tabular}

Table 2: Forced degradation studies result

\begin{tabular}{lcccccc}
\hline \multirow{2}{*}{ Stress condition } & \multicolumn{2}{c}{ Sofosbuvir } & \multicolumn{2}{c}{ Velpatasvir } & \multicolumn{2}{c}{ Voxilaprevir } \\
\hline & \%Assay & \%D & \%Assay & \%D & \%Assay & \%D \\
Acid & 94.23 & 5.77 & 94.04 & 5.96 & 94.14 & 5.86 \\
Base & 95.35 & 4.65 & 95.10 & 4.9 & 94.49 & 5.51 \\
Neutral & 99.37 & 0.63 & 99.51 & 0.49 & 99.67 & 0.33 \\
Peroxide & 95.95 & 4.05 & 95.58 & 4.42 & 96.61 & 3.39 \\
Photolytic & 97.73 & 2.27 & 97.58 & 2.42 & 99.08 & 0.92 \\
Thermal & 98.22 & 1.75 & 96.43 & 3.57 & 98.71 & 1.29 \\
\hline
\end{tabular}

$\%$ D- Percentage Degradation

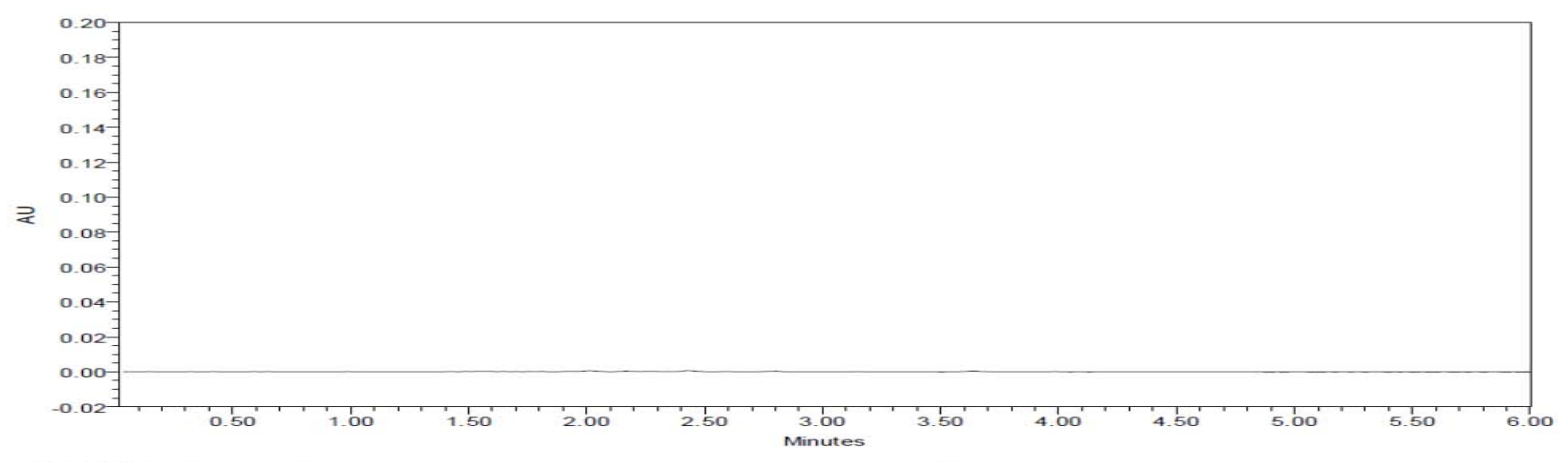

Figure 5: Blank chromatogram

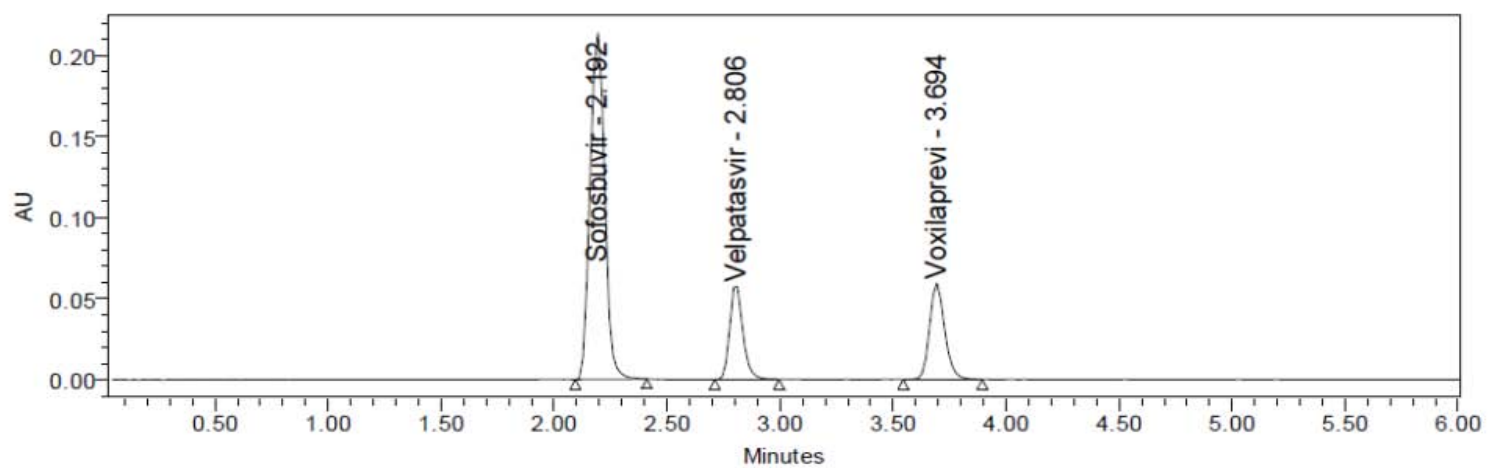

Figure 6: Standard chromatogram 


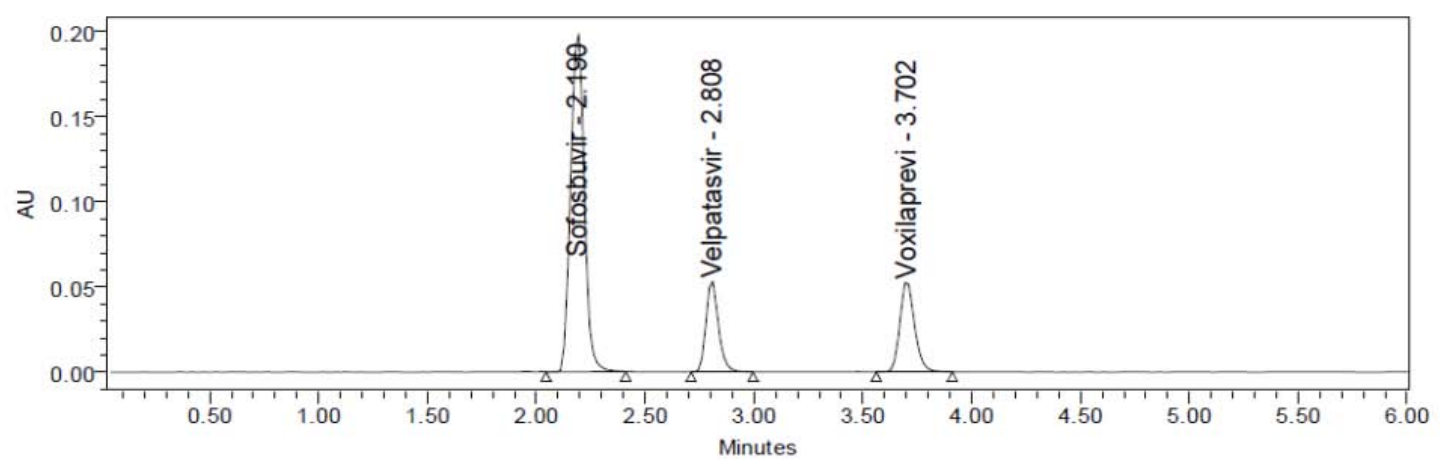

Figure 7: Sample chromatogram

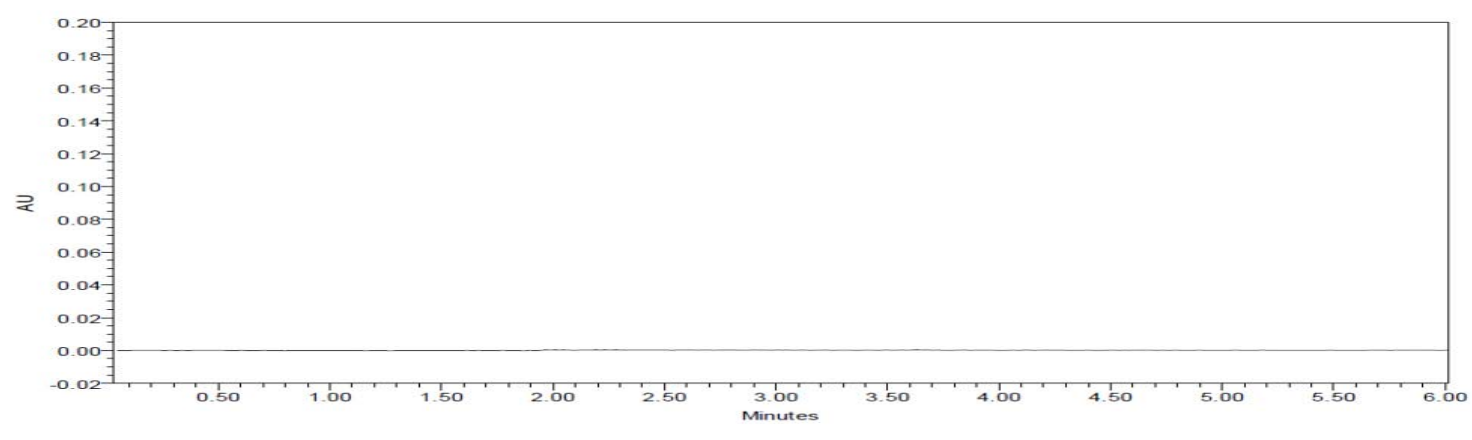

Figure 8: Placebo chromatogram

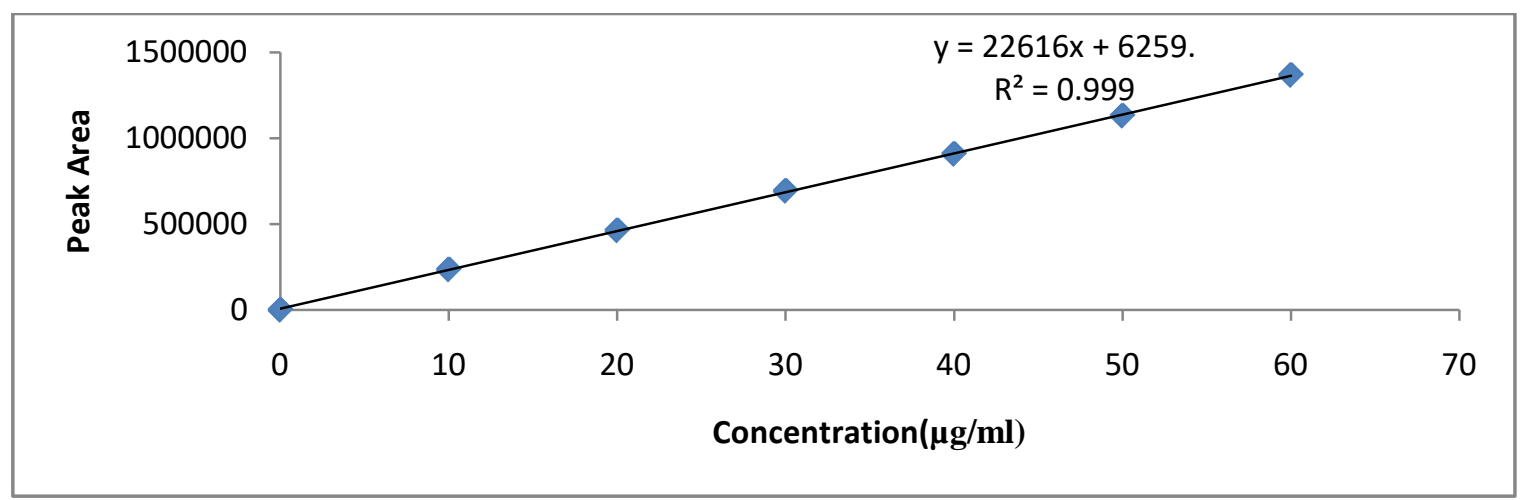

Figure 9: Linearity plot of Sofosbuvir

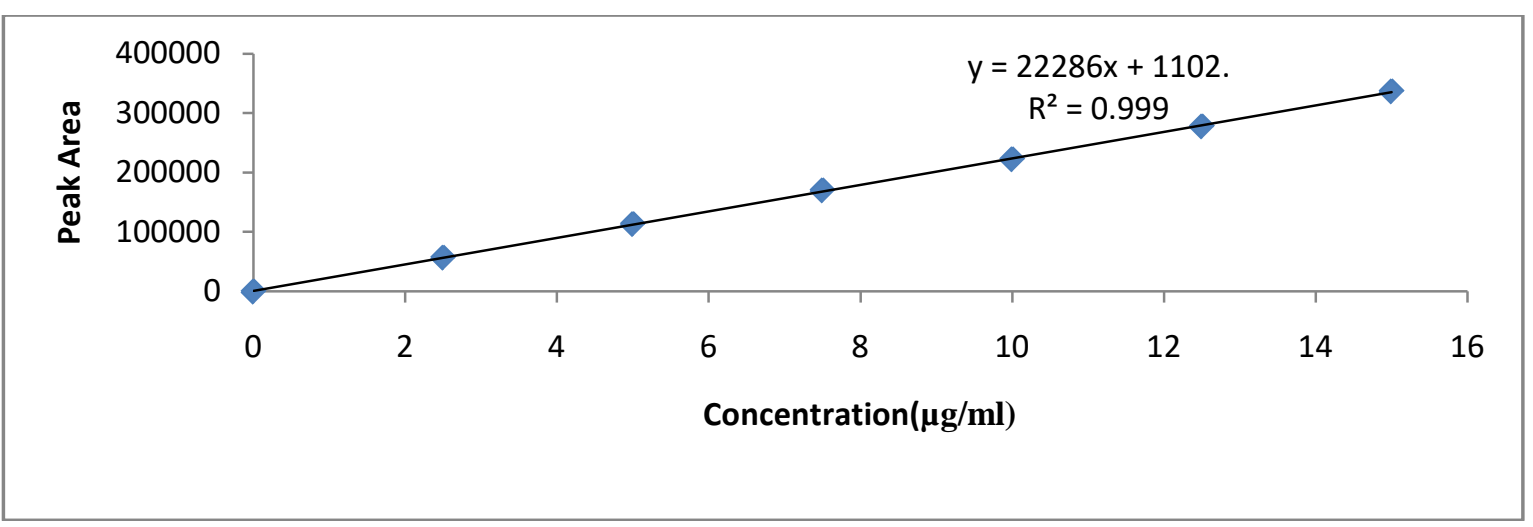

Figure 10: Linearity plot of Velpatasvir 


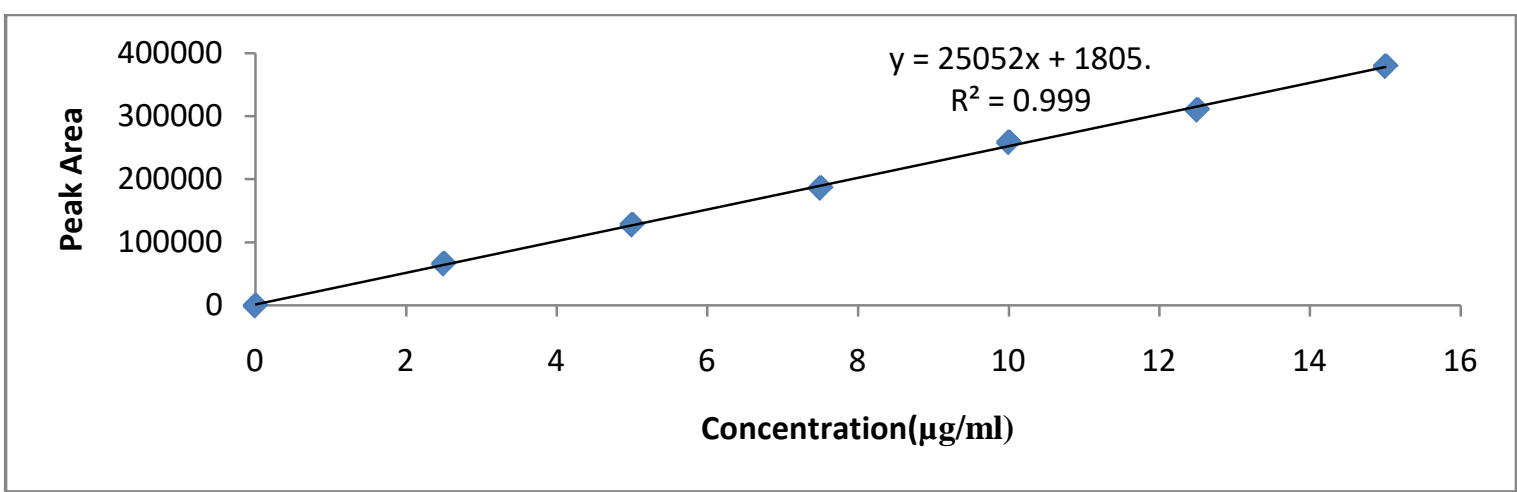

Figure 11: Linearity plot of Voxilaprevir

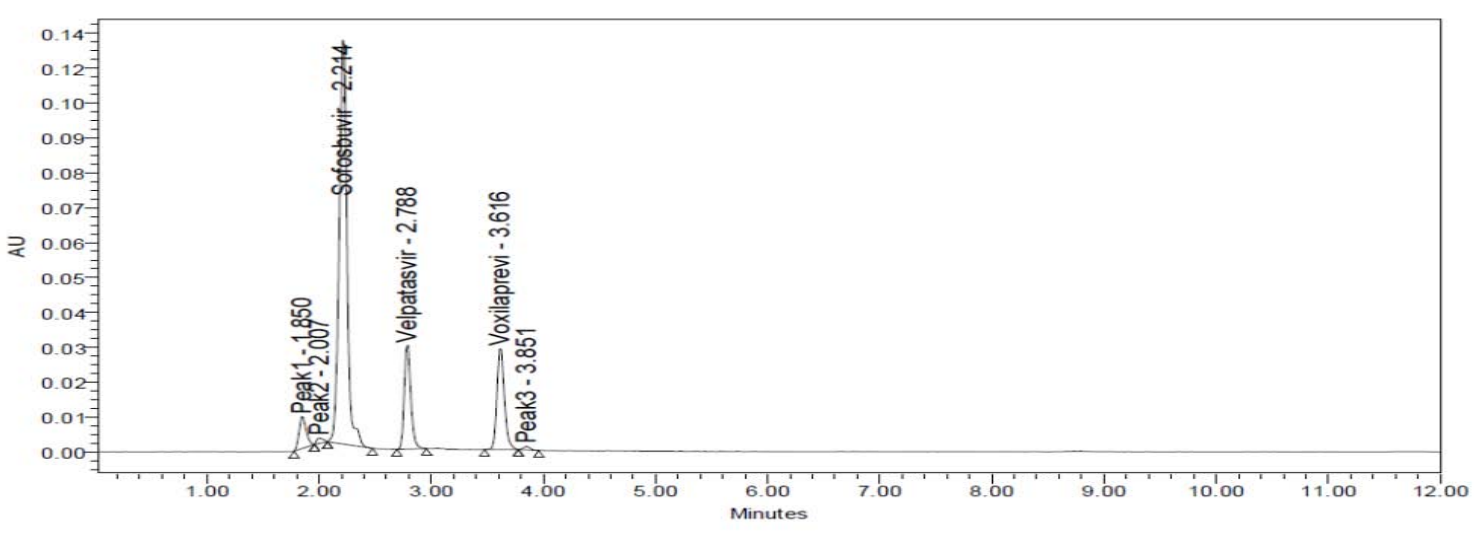

Figure 12: HPLC Chromatogram of Acid Degraded sample

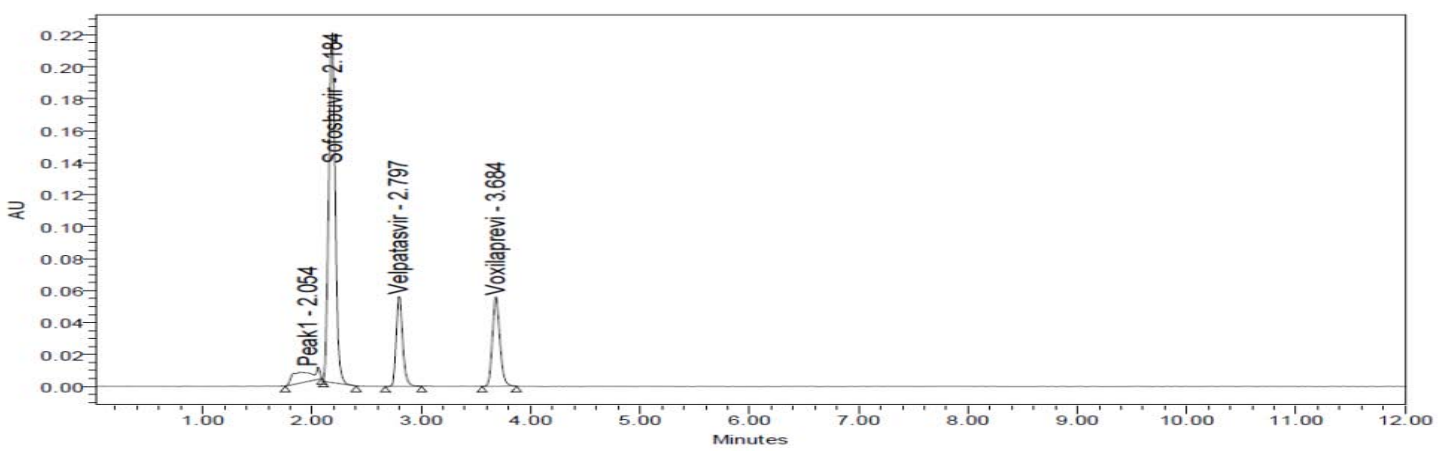

Figure 13: HPLC Chromatogram of Alkali Degraded sample

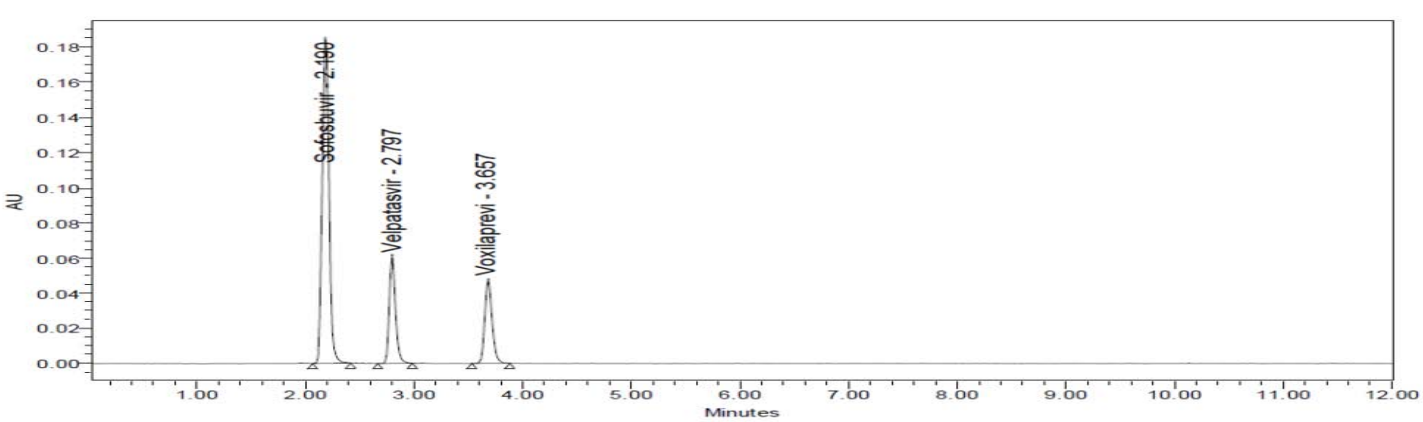

Figure 14: HPLC Chromatogram of Peroxide Degraded sample 


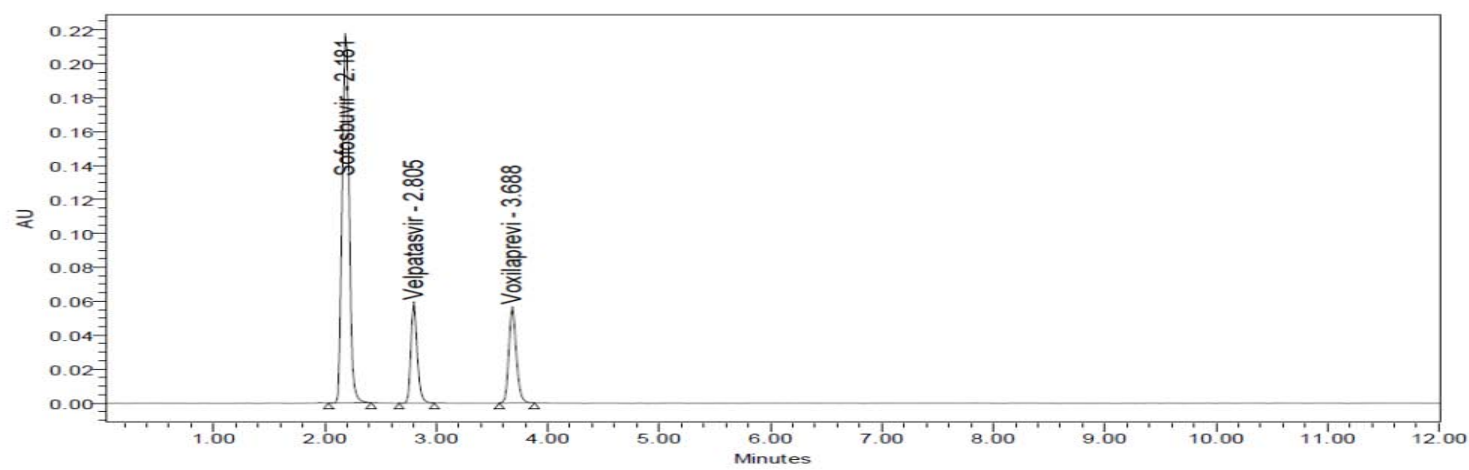

Figure 15: HPLC Chromatogram of Thermal Degraded sample

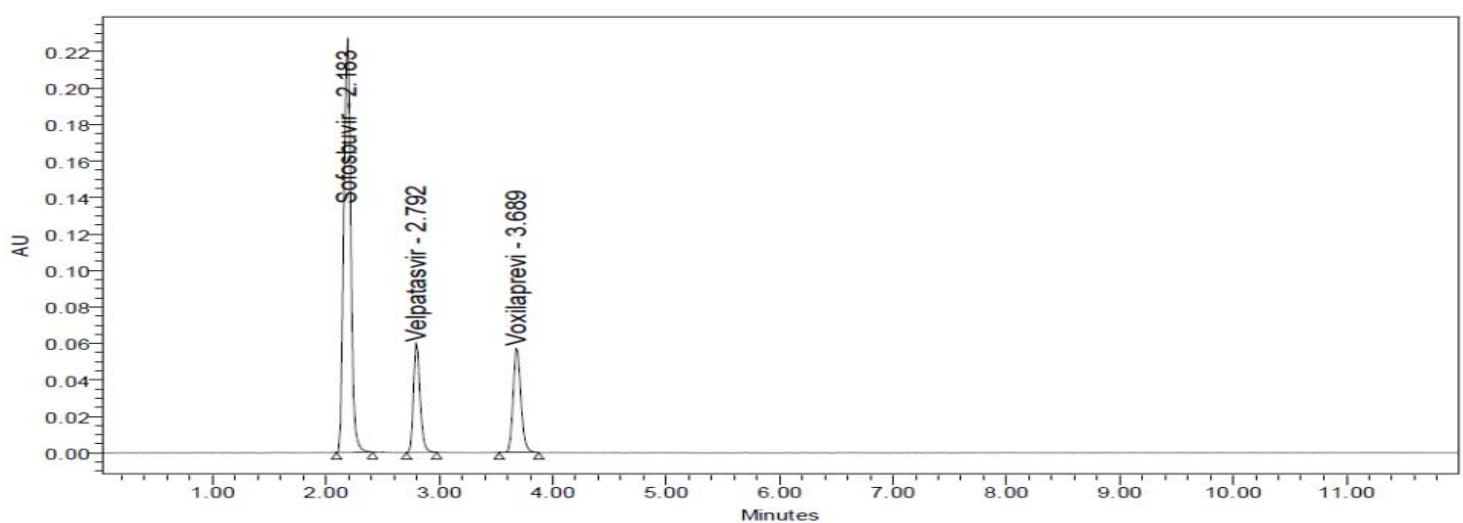

Figure 16: HPLC Chromatogram of UV Degraded sample

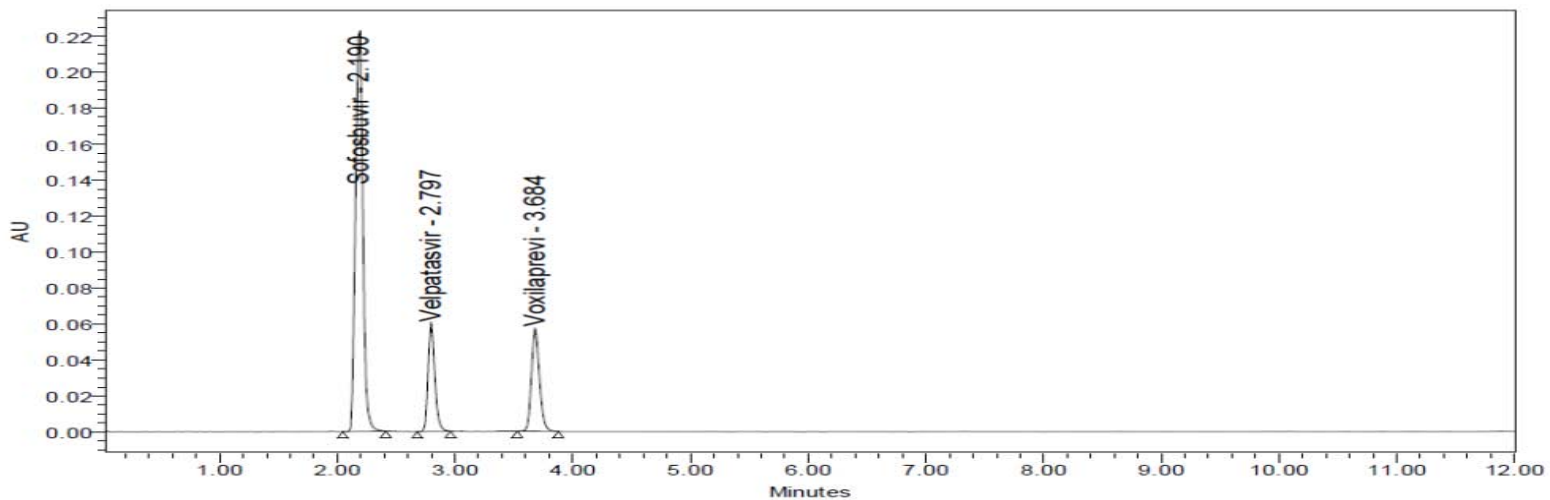

Figure 17: HPLC Chromatogram of Neutral Degraded sample

\section{Discussion}

For the development of a new method for the simultaneous estimation of Sofosbuvir, Velpatasvir, and Voxilaprevir in bulk and pharmaceutical dosage form initially many mobile phases and many columns were tried to elute the drug peak with less tailing factor, more plate count and more resolution.

Waters HPLC Agilent C18 $(250 \mathrm{~mm} \times 4.6 \mathrm{~mm}$, $5 \mu)$ column and Buffer: Acetonitrile $(55: 45 \% \mathrm{v} / \mathrm{v})$ as mobile phase were selected based on peak parameters. The detection wavelength was found to be $220 \mathrm{~nm}$.
Prepared standard solution, sample solution, and blank solution were injected into the HPLC system and system suitability parameters were noted as summarized in Table 1 along with chromatograms as shown in fig. 4, 5, 6 and 7 respectively.

The developed method was found to obey Beer's law in the concentration range of $10-60 \mu \mathrm{g} / \mathrm{ml}$ for Sofosbuvir, 2.5-15 $\mu \mathrm{g} / \mathrm{ml}$ for velpatasvir and 2.5-15 $\mu \mathrm{g} / \mathrm{ml}$ for Voxilaprevir with a correlation coefficient of 0.999 each respectively. A linear graph was plotted between concentration and peak area as shown in fig. 
9.10 and 11 respectively and results are summarized in Table 1.

The method was found to be accurate as the \% recovery was $98.50 \%-101.50 \%$ for all the three drugs and was within the limits. The \%RSD was found to be less than 1 for all the three drugs indicates that the method was precise. The method was found to be specific, as there is no interference of retention time of placebo peak with that of drug peak. The placebo chromatogram was shown as fig. 8.

Forced degradation studies results indicate that the drug was found to be stable in various stress conditions as net degradation was found to be within the limits. The chromatograms were shown in fig. 12-17 and results were summarized in Table 2.

\section{COnclusion}

A specific, precise, stability-indicating method was developed for the determination of Sofosbuvir, Velpatasvir, and Voxilaprevir in pure and tablet dosage form using RP-HPLC. The method was validated by using various validation parameters and the method was found to be linear, precise, accurate, specific and robust. From the degradation, studies conducted it is concluded that Sofosbuvir, Velpatasvir, and Voxilaprevir were stable at high concentrations of Acid, Base, Peroxide, Thermal, UV and Water stress study conditions. The run time was $5 \mathrm{~min}$ which enables rapid quantitation of many samples in routine and quality control analysis of tablet formulations.

\section{AcKnOWLedgment}

The authors are thankful to the pharma research solutions, Hyderabad for providing the Sofosbuvir, Velpatasvir, and Voxilaprevir as the gift samples and also for providing required facilities to carry out this research work.

\section{Conflict of Interests}

The authors claim that they have no conflict of interest. It has not meant to publish elsewhere. Moreover, it has not meant simultaneously presented for publication elsewhere.

\section{References Références Referencias}

1. https://www.who.int/news-room/fact-sheets/detail/ hepatitisC

2. http://www.wikipedia.com/sofosbuvir

3. http://www.wikipedia.com/velpatasvir

4. http://www.wikipedia.com/voxilaprevir

5. Sandhya Rani J and Devanna N. Development and validation of RP-HPLC method for the simultaneous estimation of Sofosbuvir, velpatasvir, and voxilaprevir in bulk and tablet dosage forms. Rasayan chem. Journal, 2018; 11(I) 2:452 - 459.
6. Sandhya Rani J, Devanna N. New RP-HPLC method development and validation for simultaneous estimation of sofosbuvir and velpatasvir in a pharmaceutical dosage form. International Journal of Engineering Technology Science and Research, 2017; 4,(11):145-152.

7. Geetha Susmitha A and Rajitha G. Development and validation of stability indicating UPLC method for simultaneous estimation of sofosbuvir and velpatasvir in a tablet dosage form. International journal of pharmaceutical sciences and research, 2018; 9(11): 4764-4769.

8. Lakshmana Rao A and Pallavi A. Method Development and Validation of Stability Indicating RP-HPLC Method for Simultaneous Estimation of Sofosbuvir and Velpatasvir in Tablet Dosage Form. Pharmaceutical Sciences \& Analytical Research Journal, 2019; 2(1):1-8.

9. Balaswami, B; Ramana, P Venkata; Rao, B Subba; Sanjeeva, P. A New Simple Stability-Indicating RPHPLC- PDA Method for Simultaneous Estimation of Triplicate Mixture of Sofosbuvir, Velpatasvir, and Voxilaprevir in Tablet Dosage Form. Research Journal of Pharmacy and Technology, 2018; 11(9):4147-4156.

10. Memthoibi Devi L, Dr.Rama Mohan Reddy T, Dr.Abbulu K. Simultaneous determination and validation of third generation antiviral drugs by RPHPLC method. International journal of pharmacy and analytical research, 2010; 8(1):1-8.

11. Lalitha KV, Raveendra Reddy J, and N Devanna N. Stability indicating RP-HPLC method development and validation for estimation of Sofosbuvir in a pharmaceutical dosage form. The Pharma Innovation Journal, 2018; 7(5):656-662.

12. ICH: Q2 [R1], Validation of analytical procedures: text and methodology; 2005.

13. ICH: Q2B. Harmonized Tripartite Guideline, Validation of Analytical Procedure: Methodology, IFPMA, in Proceedings of the International Conference on Harmonization, Geneva; 1996.

14. Ngwa G. Forced degradation studies as an integral part of HPLC stability indicating method development. Drug delivery Technol 2010; 10:56-59. 